\title{
Cerebral palsy: why we must plan for survival
}

\author{
P M Evans, S J W Evans, E Alberman
}

\begin{abstract}
The survival of children in the South East Thames region, born between 1970 and 1979 and diagnosed as having some form of cerebral palsy was investigated. Of the 732 children studied, $651(90 \%)$ are still alive, and hence cerebral palsy must be regarded as a condition with which people live rather than a condition of which they die. Survival varies considerably among the different diagnostic groups: those suffering from spastic quadriplegia, dyskinetic and 'mixed' cerebral palsy are most severely affected. Our evidence suggests that, though immobility and severe mental subnormality are the strongest predictors of mortality in children with cerebral palsy, the majority of even the most severely affected patients survive to adulthood. It is therefore appropriate to plan for their survival by funding and evaluating programmes to maximise health, independence, and quality of life.
\end{abstract}

Cerebral palsy is costly. In recent years doctors have become increasingly aware of the rising cost of settlements in cases in which it was considered that the condition was caused by medical negligence; the consequent escalation in subscriptions to medical defence organisations; and the introduction of new arrangements to indemnify doctors working within the NHS. Most doctors have little contact with affected persons and their families, however, and can only imagine the other financial and personal costs.

Despite the paucity of published information on the life expectancy of patients with cerebral palsy, services that will maximise the quality of life of survivors need to be planned and resourced. Researchers have followed up affected children, but typically the number of cases has been small, and in some studies the population has been selected by the need for long term institutional care. ${ }^{1-3}$ The existence of a register of children with cerebral palsy in the South East Thames region born from 1970 to 1979 allowed us to trace cases to find out whether or not they had died, and has made possible calculations based on 732 cases covering the full range of severity. The survival of children suffering from different types of cerebral palsy and the effect of additional impairments on survival is presented.

Patients and methods

A register of children with cerebral palsy born from 1970 to 1979 in the South East Thames region, or resident in the region at the time of ascertainment, was assembled between 1978 and 1981 using multiple sources. ${ }^{4}$ In 1985 a follow up study was undertaken by contacting paediatricians in the region to find out the current whereabouts of the children and any change in diagnosis. In 1988 the status of each child was further established using the resources of the National Health Service Central Register (NHSCR) at Southport, through which body notification of any change in status continues to be received.

The original study comprised 816 cases, with a prevalence of about $2 / 1000$ live births from 1970 to 1974 , which suggests that ascertainment was reasonably complete in the first half of the study period. Of these 816 cases, 76 have not been included in this presentation as their diagnosis was uncertain or was revised by the paediatrician responsible for their care: 14 of them were described as having become clinically normal, in 49 a diagnosis or provisional diagnosis of cerebral palsy was revised, and in 13 cases it has not been possible to confirm a provisional diagnosis. Though it might not be correct to exclude all these cases from the calculation-for example-of trends in prevalence, we considered it appropriate to exclude them from the analysis of survival.

Sixteen cases were excluded for administrative reasons: two of the children had resided only briefly in the region, two had been notified twice under different names and from different parts of the region, and two born in 1980 had been included under incorrect dates of birth. A further 10 cases could not be traced by NHSCR and hence could have been duplicates, so were excluded. This left 724 of the original 816 cases, and to these have been added a small number of new cases that were ascertained only after they had died. In 1986 a search of death certificates to find additional cases of cerebral palsy was undertaken by the Office of Population Censuses and Surveys (OPCS) on our behalf (1970 to 1974 births only), and yielded seven new cases. One further case was found by reference to a district deaths register. Of these eight cases, three had died aged less than 3 months, and none was aged more than 2 years at death. After the exclusions described, the new cases brought the total number of children included in the present analysis to 732 . Survival analysis was done by standard methods, computer programs BMDP1L and BMDP2L.

Results

Of the 732 cases, 73 had died and 651 were
Correspondence to: Dr Evans.

Accepted 2 July 1990 
listed as alive at the end of December 1989, although the possibility of a delay in notification of a death to us by NHSCR cannot be excluded. Eight cases were lost to follow up on a known date-for example, when moving overseas; as these cases have a known duration of survival it is possible to include them with the 'alive' group in the analysis of survival.

\section{SURVIVAL BY YEAR OF BIRTH}

Survival by year of birth is shown in table 1 . The smaller number of cases in the later years illustrates the point made in the earlier paper that though ascertainment was considered virtually complete in the earlier years, this was not so for the later years. ${ }^{4}$ The high percentage of deaths in children born in 1979 may be accounted for by the fact that the more severely affected cases were most likely to have been firmly diagnosed as having cerebral palsy before the study period ended in 1981, when they were still relatively young.

RELATIVE RISK OF DEATH CALCULATED USING NATIONAL DATA

There are 420 boys and 312 girls who have an average of 15.0 years of follow up ( 16.0 years for those who have not died) covering the ages 0 to 19.9 years. Forty seven boys and 26 girls died, while 11.5 and 6.4 deaths, respectively, would have been expected if death rates in the general population data for England and Wales, 1970

Table 1 Survival of cases of cerebral palsy by year of birth

\begin{tabular}{lclcr}
\hline $\begin{array}{l}\text { Year of } \\
\text { birth }\end{array}$ & $\begin{array}{l}\text { No } \\
\text { alive }\end{array}$ & $\begin{array}{l}\text { No } \\
\text { lost to } \\
\text { follow up }\end{array}$ & $\begin{array}{l}\text { No (\%) } \\
\text { dead }\end{array}$ & Total \\
\hline 1970 & 85 & 1 & $16(16)$ & 102 \\
1971 & 106 & 1 & $11(9)$ & 118 \\
1972 & 95 & 1 & $7(7)$ & 103 \\
1973 & 85 & 1 & $9(9)$ & 95 \\
1974 & 68 & 0 & $10(13)$ & 78 \\
1975 & 59 & 0 & $2(3)$ & 61 \\
1976 & 61 & 2 & $5(7)$ & 68 \\
1977 & 40 & 1 & $4(11)$ & 46 \\
1978 & 33 & 1 & $4(11)$ & 38 \\
1979 & 19 & 0 & $4(17)$ & 23 \\
\hline Total & 651 & 8 & $73(10)$ & 732 \\
\hline
\end{tabular}

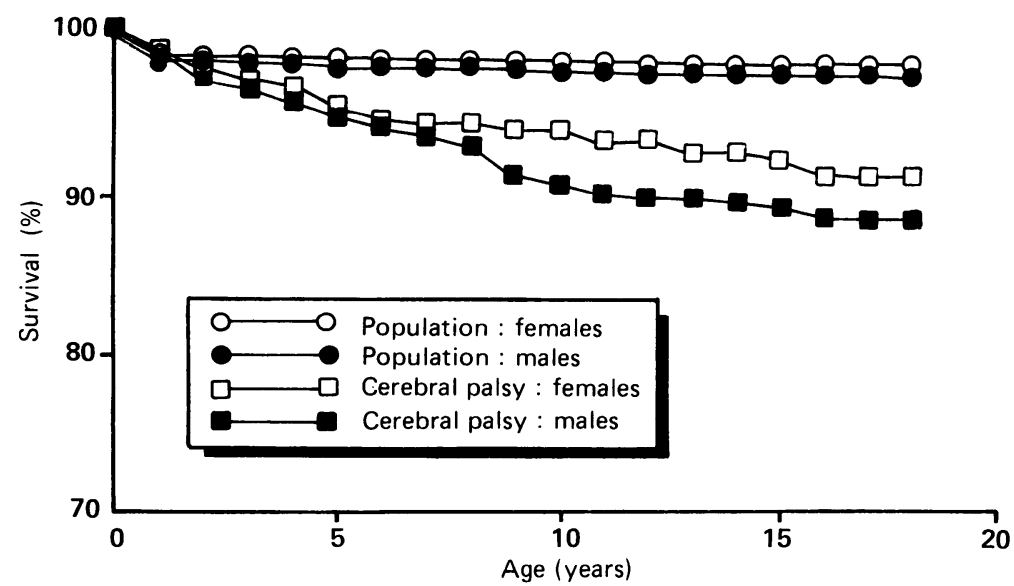

Figure 1 Comparison of survival curves for children (females and males) in the general population in England and Wales (1970-2) and children with cerebral palsy born between 1970 and 1979 in the South East Thames region.
2 had applied. In the first year of life the number of deaths was lower than expected for both boys and girls, but from the ages of 1 to 19 the numbers are much higher: 41 boys and 22 girls compared with the expected 3.20 and 1.67 (fig 1).

Although the death rate among boys is higher than that among girls, the difference is not statistically significant, and is in line with the male-female difference in the general population. Though there is considerable fluctuation from year to year, there is no evidence of any trend up or down in this relative risk from the age of 1 to 19 years in either sex, though the number of deaths is too small to draw firm conclusions.

\section{FACTORS AFFECTING SURVIVAL}

Type of cerebral palsy

The cases subdivided by type of cerebral palsy are shown in table 2 . In most cases this is based on the diagnosis given by the paediatrician responsible for each child's care in the original study, although in a few cases this has been enhanced by additional information obtained from the death certificate. Most of the deaths (67\% of those in which the type of cerebral palsy is known) occurred in the spastic quadriplegia (and tetraplegia) group, the children commonly having additional impairments, especially in mental ability. Their impaired survival is, however, only in part attributable to the association with severe subnormality (see multivariate analysis below). The survival of cases in this and two other diagnostic groups is shown in figure 2 . In view of the fact that spasticity is not always mentioned if another type of cerebral palsy is also present, we did not consider it appropriate to present the results for the ataxic or dyskinetic children separately from the ataxic spastic or dyskinetic spastic children. The unsatisfactory term 'mixed' is used to describe a small group of cases: this can mean different things to different people, and clinicians do not always specify the 'ingredients' of the 'mixture' when using it to describe cases. We have used it to cover those who have a mixture of ataxia and some sort of dyskinesia, often with spasticity. Most suffer from additional impairments, and this group has an appreciably reduced survival rate (table 2).

Table 2 Deaths by type of cerebral palsy

\begin{tabular}{|c|c|c|c|}
\hline & $\begin{array}{l}\text { No (\%) } \\
\text { alive } \\
\text { or lost } \\
\text { to follow up }\end{array}$ & $\begin{array}{l}\text { No (\%) } \\
\text { dead }\end{array}$ & Total \\
\hline $\begin{array}{l}\text { 'Hypotonia'* } \\
\text { Hemiplegia/monoplegia } \\
\text { Diplegia/paraplegia } \\
\text { Quadriplegia } \\
\text { Ataxic (with or without } \\
\text { spasticity) } \\
\text { Dyskinetic (with or } \\
\text { without spasticity) } \\
\text { 'Mixed' } \\
\text { Type not known }\end{array}$ & $\begin{aligned} & 10(91) \\
& 153(99) \\
& 100(100) \\
& 107(74) \\
& 64(98) \\
& 108(91) \\
& 9(75) \\
& 108(86)\end{aligned}$ & $\begin{array}{l}1(9) \\
2 \dagger(1) \\
0 \\
37(26) \\
1 \neq(2) \\
11(9) \\
3(25) \\
18(14)\end{array}$ & $\begin{array}{r}11 \\
155 \\
100 \\
144 \\
65 \\
119 \\
12 \\
126\end{array}$ \\
\hline Total & $659(90)$ & $73(10)$ & 732 \\
\hline
\end{tabular}

*Not necessarily hypotonic cerebral palsy.

tIn one case the cause of death was certified as accidental; the other had spina bifida and hydrocephalus in addition to a hemiplegia.

†Spastic quadriplegia with ataxia, plus hydrocephalus. 


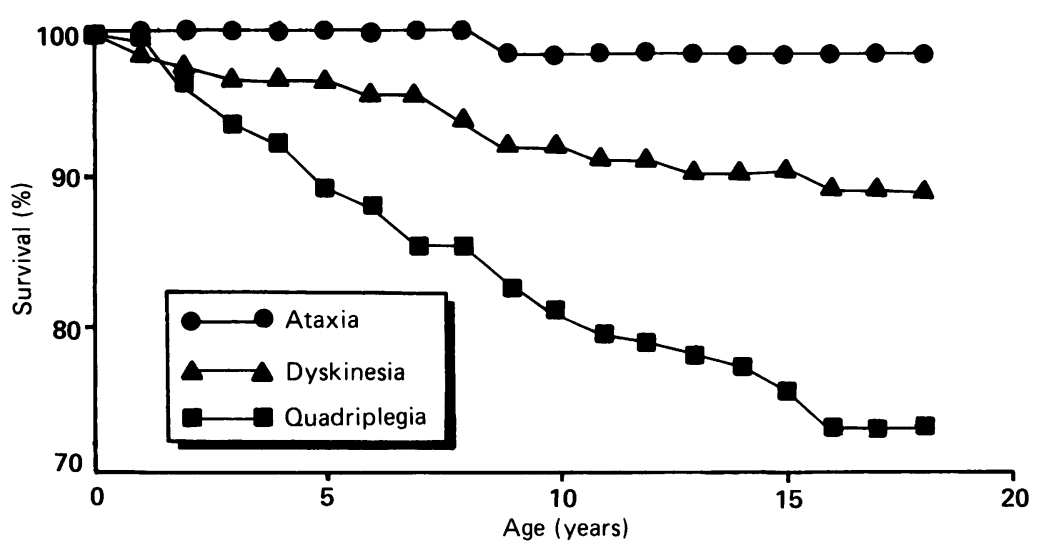

Figure 2 Survival curves for children with the three types of cerebral palsy born between 1970 and 1979 in the South East Thames region.
Table 4 Deaths by mobility and mental ability (444 cases with complete data)

\begin{tabular}{lccc}
\hline & $\begin{array}{l}\text { No (\%) } \\
\text { alive } \\
\text { or lost } \\
\text { to follow up }\end{array}$ & $\begin{array}{l}\text { No (\%) } \\
\text { dead }\end{array}$ & Total \\
\hline $\begin{array}{l}\text { Immobile and severely } \\
\begin{array}{c}\text { subnormal } \\
\text { Immobile but not }\end{array}\end{array}$ & $65(69)$ & $29(31)$ & 94 \\
$\begin{array}{l}\text { severely subnormal } \\
\begin{array}{l}\text { Severely subnormal } \\
\text { but not immobile }\end{array}\end{array}$ & $27(93)$ & $2(7)$ & 29 \\
$\begin{array}{l}\text { Neither immobile nor } \\
\text { severely subnormal }\end{array}$ & $258(99)$ & $2(3)$ & 61 \\
\hline Total & $409(92)$ & $35(8)$ & 444 \\
\hline
\end{tabular}

seizures that occur only early in life, and persistent seizures, may elucidate any effect on survival, but these data are not available at present.

\section{Mental ability}

In 504 of the 732 cases an assessment of mental ability was available, and no child known to have normal mental ability has died. Table 3 shows the number of deaths that have occurred in each mental ability group. The effect of mental ability on survival is further discussed in the section on multivariate analysis.

\section{Mobility}

Mobility (as assessed in the original study when the oldest child was aged less than 12 years) is known in 453 cases, and is a function of both physical and mental factors. Of the 124 children who were confined to bed, or to a wheelchair that they did not propel themselves ('immobile'), 31 (25\%) are dead. There have been only four deaths in the remaining 329 children known to be mobile. The degree of mobility of 38 children who have died is unknown; 15 of them died aged 18 months or less, so their mobility is likely to have been limited by age notwithstanding other factors. The strong association between immobility and severe subnormality leading to appreciably impaired survival is shown in table 4 , and discussed in the section on multivariate analysis.

\section{Seizures}

Preliminary univariate analysis demonstrated an association between the presence of epilepsy and reduced survival. This finding is, however, the result of the strong association between epilepsy and mental subnormality. It is possible that future analyses that discriminate between

Table 3 Deaths by mental ability (504 cases)

\begin{tabular}{lllr}
\hline & $\begin{array}{l}\text { No (\%) } \\
\text { alive } \\
\text { or lost } \\
\text { to follow up }\end{array}$ & $\begin{array}{l}\text { No (\%) } \\
\text { dead }\end{array}$ & Total \\
& $111(100)$ & 0 & \\
\hline Normal & $84(97)$ & $3(3)$ & 111 \\
Slight impairment & $112(96)$ & $5(4)$ & 117 \\
Moderate impairment & $149(79)$ & $40(21)$ & 189 \\
Severe impairment & $456(90)$ & $48(10)$ & 504 \\
\hline Total & 48 \\
\hline
\end{tabular}

\section{Hydrocephalus}

The original assessment did not include a specific question regarding the presence or absence of hydrocephalus, but its presence was mentioned in 30 cases, of whom eight $(27 \%)$ are now dead. Of the remaining 702 cases who are not known to have hydrocephalus, $65(9 \%)$ are dead. Of the eight cases with hydrocephalus who died, six are known to have been severely subnormal, and mental ability was not known in the remaining two cases; three were immobile, one had limited mobility, and mobility was not known in the four remaining cases. In each case the death certificate included a reference to hydrocephalus.

\section{Birth weight and sex}

So far data analysis has shown that in those children who survive the first few months of life, neither birth weight nor sex has any important impact on survival to the age of 18 .

\section{'Anticipated future prospects'}

When originally assessing children for the study, paediatricians were asked to express an opinion on 'anticipated future prospects'. Of the 732 cases in the current analysis, an opinion was expressed for 438 cases, of whom 173 (39\%) were expected to require permanent care. Of these, $145(84 \%)$ are still alive.

\section{MULTIVARIATE ANALYSIS}

There were 444 patients for whom data were sufficiently complete to permit multivariate analysis, and of these $35(8 \%)$ have died. Using proportional hazards regression, the effects of mobility, mental ability, seizures, sex, and birth weight were examined together. The results are expressed as risks for those with a factor relative to those without the factor. This showed that immobility and severe mental subnormality were the two strongest predictors of mortality, and they both made contributions independently of the other. Using the 'mobile' cases to determine the baseline value, being 'immobile' is associated with a relative risk of $10.8(p=$ 
$0.0001,95 \%$ confidence interval (CI) 3 to 34 ); being severely subnormal has an independent relative risk of $4.7(p=0.01,95 \% \mathrm{CI} 1.5$ to 14.7). Among the group of 94 children suffering from both immobility and severe mental subnormality there have been 29 deaths $(0.59$ expected), and the cumulative death rate calculated using life table analysis is $33 \%$. There is evidence that diagnostic category is also relevant, so that for those children with spastic quadriplegia who are both immobile and severely subnormal the cumulative death rate is nearly $43 \%$. There was no important additional contribution from the presence of seizures, sex or birth weight. (Birth weight was unavailable in 117 of the 444 cases.)

\section{CERTIFIED CAUSE OF DEATH}

Copies of death certificates have been received from NHSCR for all 73 deaths. Mention of a condition classifiable as cerebral palsy appeared somewhere on 45 of the death certificates $(62 \%)$, but only $16(22 \%)$ of the death drafts had 'Infantile cerebral palsy' (International Classification of Diseases code 343-) as the underlying cause of death; this includes two cases where the wording on the death certificate was 'cerebral birth anoxia'. The small proportion of cases coded 343- means that cerebral palsy is grossly under-represented in the available mortality statistics for England and Wales, which, except for 1985 and 1986, include only the underlying cause of death and not multiple causes.

Epilepsy featured in $14(19 \%)$ death certificates, and mental subnormality in $15(21 \%)$. In 57 cases $(78 \%)$ there was a respiratory (or cardiorespiratory) cause of death, most commonly a respiratory infection. It should be noted that these figures are not mutually exclusive. A full description of the information on causes of death will be published separately. It is worthy of note, however, that chickenpox, measles, and pertussis appeared as a cause of death in one case each.

\section{Discussion}

Most of the children (90\%) are still alive, and are now aged between 10 and 20 years. The widely differing prospects of the diagnostic groups underlines the need for a generally accepted method of describing the motor deficit in affected children to sharpen the focus. ${ }^{5}$ The present diagnostic 'anarchy' is clearly unsatisfactory, and clouds discussion not only of future prospects but also regarding possible aetiologies.

'Cerebral palsy' is a diagnostic label that is usually applied only after some weeks or months of investigation and observation. Hence children who died in the first few months of life were less likely to have been defined as 'cases'. This means that the total number of deaths occurring in the first year of life is artificially low, and gives a risk of death for this period that is lower than that of the general population.

Of the children with cerebral palsy born in the early 1970 s, about $85 \%$ of those who survived the first few months of life may be expected to reach the age of 20 years. The high proportion of survivors in all groups, even among those expected to require permanent care, is likely to come as a surprise to those (some doctors as well as lay people) who believe that most children severely affected by cerebral palsy die in the first few years of life.

Immobility and severe mental subnormality seem to be the most important factors influencing survival: where one of these factors is present survival is slightly reduced, but the effect is most pronounced when both factors are present. Eyman et al concluded that non-ambulation and low intelligence quotient (IQ) were associated with impaired survival in their studies of persons with mental retardation, some of whom also suffered from cerebral palsy. ${ }^{6}$ They also reported that epilepsy was associated with impaired survival. They did not state, however, whether or not they had used multivariate analysis to eliminate any confounding effect of the association of epilepsy with non-ambulation and low IQ.

In 1983 Carter and Jancar drew attention to the increased longevity of mentally handicapped persons in hospital, which they attributed to treatment with new drugs (in particular for epilepsy), better diet, care, and environment. ${ }^{7}$ These factors may be expected to have made an impact on the survival of children and adults with cerebral palsy. Changes in the contraindications for immunisation against some common childhood illnesses will mean that the many children with cerebral palsy who also suffer from seizures will no longer automatically be denied protection, and thus some lives may be prolonged. This is one of the many factors which need to be borne in mind when seeking to relate the survival of the children in this study to that of children being born now.

The move from institutional to community care for many handicapped children and adults has (or should have) prompted a reappraisal of their long term needs. While the debate continues regarding the value or otherwise of conductive education or other forms of intensive daily treatment, it is apparent that some children with cerebral palsy are not receiving even the most basic treatment (for example, one session a week with a physiotherapist for a child with mobility problems). This is a fact which the authors are confirming from the preliminary results of a survey of affected children born in the 1980s in the North East Thames region (PM Evans et al, unpublished observations).

One might reflect that further research may not necessarily produce overwhelming financial justification for greater expenditure on daily treatment programmes. If, for example, one succeeds in showing conclusively that an intensive mobilisation programme instituted as soon as a diagnosis of cerebral palsy is made reduces the likelihood of immobility in adult life, one might also show that this regimen improves the survival of those patients who, in spite of daily treatment, remain immobile and require total care, thus negating any financial benefit. It is vital, therefore, that those responsible for health care planning give appropriate weight to indices of quality of life on the part of the patient, and 
his or her family, when assessing the long term value of treatment.

We hope that cerebral palsy will now be regarded by all as a condition with which one lives rather than a condition from which one dies. The evidence from this study permits realistic calculations of the expected needs of children suffering from cerebral palsy, and could facilitate the long term planning of their health care at both local and national level. It also underlines the need to investigate the effectiveness of programmes designed to ensure that each patient reaches his or her full potential. Some will inevitably remain totally dependent, but where this can be avoided the necessary resources must be made available to prevent it; where it cannot the long term care needs must be properly assessed and funded.

The authors gratefully acknowledge the cooperation of clinicians and administrative staff in the South East Thames region, the provision of survival and death certificate data by the Office of
Population Censuses and Surveys and the National Health Service Central Register, and financial assistance from the Spastics Society.

1 Pollock GA, Stark G. Long-term results in the management of 67 children with cerebral palsy. Dev Med Child Neurol 1969;11:17-34

2 Von Wendt L, Rantakallio P, Saukkonen A-L, Tuisku M, Makinen H. Cerebral palsy and additional handicaps in a 1year birth cohort from Northern Finland-a prospective follow-up study to the age of 14 years. Ann Clin Res 1985;17:156-61.

3 Kudrjavcec T, Schoenberg BS, Kurland LT, Groover RV. Cerebral palsy: survival rates, associated handicaps, and distribution by clinical subtype (Rochester, $\mathrm{MN}$, 19501976). Neurology 1985;35:900-3.

4 Evans $P$, Elliott M, Alberman E, Evans S. Prevalence and disabilities in 4 to 8 year olds with cerebral palsy. Arch Dis Child 1985;60:940-5.

5 Evans P, Johnson A, Mutch L, Alberman E. A standard form for recording clinical findings in children with a motor for recording clinical findings in children with a motor 1989;31:119.

6 Eyman R, Chaney R, Givens C, Lopez E, Lee C. Medical conditions underlying increasing mortality of institutionalised persons with mental retardation. Ment Retard 1986;24:301-6.

7 Carter G, Jancar J. Mortality in the mentally handicapped: a 50 year survey at the Stoke Park group of hospitals (19301980). F Ment Defic Res 1983;27:143-56.

British Paediatric Association Annual Meetings

University of Warwick:

16-19 April 1991

7-10 April 1992

20-23 April 1993

12-15 April 1994 